\title{
Influência da adubação nitrogenada, época de plantio e aerosporos sobre a severidade da mancha de grãos em arroz de terras altas
}

\author{
Valácia Lemes da Silva-Lobo ${ }^{1}$, Maria da Guia Lacerda ${ }^{2}$, Marta Cristina de Filippi ${ }^{1}$, Gisele Barata da Silva ${ }^{3}$, Anne \\ Sitarama Prabhu ${ }^{1}$.
}

${ }^{1}$ Embrapa Arroz e Feijão, C.P. 179, 75375-000 Santo Antônio de Goiás, GO; ${ }^{2}$ UFG, C.P 131, 74001-970, Goiânia,GO, ${ }^{3}$ UFRA, C.P. 917, 66077530, Belém, PA.

Autor para correspodência: Valácia Lemes da Silva Lobo (valacia@cnpaf.embrapa.br)

Data de chegada: 06/04/2010. Aceito para publicação em: 03/03/2011.

\section{RESUMO}

Silva-Lobo, V.L.; Lacerda, M.G.; Filippi, M.C.; Silva, G.B; Prabhu, A.S. Influência da adubação nitrogenada, época de plantio e aerosporos sobre a severidade da mancha de grãos em arroz de terras altas.Summa Phytopathologica, v.37, n.3, p.110-115, 2011.

A mancha de grãos (MG) ocupa o segundo lugar em importância econômica entre as doenças do arroz. Foi estudada a influência de níveis de adubação nitrogenada, época de plantio e concentração de esporos no ar sobre a severidade da doença no campo. A severidade de MG, na cultivar BRS Bonança, foi avaliada em duas épocas de plantio (30/11/2006 e 21/12/2006) e cinco doses de adubação nitrogenada $\left(0,30,60,120\right.$ e $240 \mathrm{~kg}$ de $\left.\mathrm{N} \cdot \mathrm{ha}^{-1}\right)$ utilizando o delineamento experimental de blocos ao acaso em esquema de parcelas subdivididas com três repetições. O efeito de dose de $\mathrm{N}$ sobre a severidade de $\mathrm{MG}$ não foi significativo. A correlação entre a severidade de $M G$ e espiguetas vazias foi positiva e significativa. A população de fungos no ar (aerosporos) foi quantificada utilizando armadilhas volumétricas,
Rotorod Sampler, desde a emissão até o amadurecimento das panículas. A mancha de grãos aumentou linearmente com tempo $(\mathrm{r}=0,98 ; \mathrm{P} \leq$ 0,01), o mesmo não ocorreu com o aumento total de fungos que variou de 0,23 a 2,97 esporos/litro de ar/minuto. Os fungos presentes no ar em ordem decrescente de concentração foram Nigrospora sp., Pyricularia oryzae, Pithomyces sp., Alternaria sp., Cercospora sp., Fusarium sp., Curvularia sp. e Bipolaris sp. Estes fungos e Phoma sp. entre outros também foram detectados no teste de sanidade de sementes. A correlação entre a quantidade de esporos de $P$. oryzae e outros fungos foi linear e positiva $(\mathrm{r}=0,80, \mathrm{P} \leq 0,01)$. O número de esporos aumentou com o aumento da umidade relativa e diminuiu com o aumento da temperatura máxima de maneira exponencial.

Palavras-chave adicionais: Oryza sativa, armadilha volumétrica, doenças de final de ciclo, epidemiologia.

\begin{abstract}
Silva-Lobo, V.L.; Lacerda, M.G.; Filippi, M.C.; Silva, G.B; Prabhu, A.S. Influence of nitrogen fertilization, planting date and air spora on grain discoloration severity in upland rice. Summa Phytopathologica, v.37, n.3, p.110-115, 2011.

Grain discoloration (GD) is ranked second among the most economically important rice diseases. The influence of nitrogen levels, planting date and air spora concentration on the disease severity was studied in the field. GD severity in the rice cultivar BRS Bonança was assessed on two planting dates (30/11/2006 and 21/12/2006), using five nitrogen levels $(0,30,60,120$ and $240 \mathrm{~kg}$ of N.ha-1) and a randomized split plot block design with three replicates. The effect of $\mathrm{N}$ level on GD severity was not significant. The correlation between GD severity and empty spikelets was positive and significant. The fungus population in the air (air spora) was quantified using the volumetric trap Rotorod Sampler from panicle emergence to

maturation. Grain discoloration linearly increased with time $(r=0.98$; $\mathrm{P} \leq 0.01$ ), but the same did not occur with the total number of fungi, which varied from 0.23 to 2.97 spores/liter of air/minute. The fungi present in the air in decreasing order of spore concentration were Nigrospora sp., Pyricularia oryzae, Pithomyces sp., Alternaria sp., Cercospora sp., Fusarium sp., Curvularia sp. and Bipolaris sp. These fungi, Phoma sp. and others were also detected in the seed health testing. The correlation between the quantity of spores of $P$. oryzae and other fungi was linear and positive $(\mathrm{r}=0.80, \mathrm{P} \leq 0.01)$. The number of spores increased with the increase in relative humidity and exponentially decreased with the increase in maximum temperature.
\end{abstract}

Keywords: Oryza sativa, volumetric spore trap, diseases of final growth stages, epidemiology.

As principais doenças de final de ciclo em arroz de terras altas incluem a brusone nas panículas [Pyricularia oryzae (Cavara) ] e a mancha de grãos associada a mais de um patógeno fúngico. Entre os patógenos causadores da mancha de grãos, Bipolaris oryzae (Breda de Haan) Schoemake [Sin. Drechslera oryzae (Breda de Haan) Subramanian \& Jain, Helminthosporium oryzae Breda de Haan]; Phoma sorghina (Sacc.) Boerema, Dorenbosch \& Van Kesteren, Alternaria padwickii
(Ganguly) Ellis (Sin. Tricochoniella padwickii Ganguly), Microdochium oryzae (Hashioka \& Yokogi) Samuels \& Hallett [Sins. Gerlachia oryzae (Hashioka \& Yokogi) W. Gams, Rhynchosporium oryzae Hashioka \& Yokogi] são importantes na redução da qualidade dos grãos. A associação de outras espécies de fungos como Drechslera spp., Curvularia spp., Nigrospora sp., Fusarium spp. com a doença, em arroz de terras altas, foram relatadas $(4,11,18,20)$. 
A análise de sementes de 42 cultivares de arroz de terras altas, produzidas em cinco locais diferentes do Brasil, mostrou que $B$. oryzae foi o patógeno mais importante no complexo mancha de grãos, seguido por P. sorghina e Gerlachia oryzae. Os demais fungos, Nigrospora sp., Curvularia spp., Fusarium spp., Epicoccum sp., Pyricularia oryzae e Trichoconiella padwickii esporadicamente apresentaram correlações com a doença (19).

A infecção de panículas das cultivares IAC 101 e IAC 103 com $B$. oryzae em condições de campo, no Estado de São Paulo, causou a diminuição em peso e número de grãos, emergência de plântulas e o peso de 100 panículas $(10,11)$.

A qualidade sanitária das sementes varia conforme o sistema de cultivo. P. oryzae, B. oryzae e $M$. oryzae foram predominantes no cultivo inundado, enquanto $P$. oryzae, $P$. sorghina e $D$. oryzae prevaleceram no sistema irrigado por aspersão (11). Na safra de 197980 uma epidemia de queima das glumelas (Phoma sorghina) no CentroOeste, provocou a redução de peso de 100 panículas variando de 29 a $45 \%$ e o rendimento engenho de 0 a $14 \%$ (14).

A incidência e severidade de mancha parda, causada por Bipolaris oryzae, são influenciadas pela nutrição das plantas, época de plantio e condições climáticas (13). A deficiência ou excesso de $\mathrm{N}$ aumenta a severidade da doença nas folhas tanto sob condições de terras altas (7) como em arroz irrigado (3). Entretanto, a mancha de grãos causada por diversos patógenos e parasitas facultativos é amplamente influenciada por condições climáticas, principalmente umidade e temperatura, não havendo registros da correlação entre a doença e fatores nutricionais, principalmente quanto ao efeito de $\mathrm{N}$ sobre a severidade de doença em arroz de terras altas. Essa doença em geral, na África, se manifesta em arroz cultivado em solos deficientes nutricionalmente, principalmente em potássio, manganês, magnésio, silício, ferro e cálcio (25).

A época de plantio e a cultivar influenciaram altamente a severidade de mancha de grãos na Índia (17). Em arroz de terras altas, no estado do Mato Grosso no Brasil, a incidência da doença foi significativamente mais baixa quando a semeadura foi realizada após a segunda quinzena de dezembro (21).

O sucesso ou o fracasso do desenvolvimento de doenças foliares e de grãos depende das condições climáticas para produção e liberação de esporos. Informações referentes à freqüência de ocorrência de fungos associados à mancha de grãos e condições climáticas favoráveis são escassas para o arroz de terras altas no Brasil. Em geral, o inóculo tem sido considerado a variável mais importante nos estudos epidemiológicos. A produção, liberação, disseminação de esporos de $P$. oryzae em arroz e seu papel na infecção, colonização e desenvolvimento da brusone em relação aos fatores climáticos tem sido assunto de diversos estudos nas últimas décadas (13). Modelos relacionando a biologia do patógeno e condições climáticas são utilizados para prever epidemias e análise de risco (6). O monitoramento do inóculo é importante para o manejo da mancha de grãos visando reduzir seu impacto a níveis toleráveis.

Embora o uso da resistência genética seja a medida de controle mais adequada e a mais econômica, os programas de melhoramento genético de arroz ainda não obtiveram sucesso, porque diferentes patógenos que infectam outras partes da planta causam a mancha de grãos e os patógenos predominantes variam conforme o local e as condições climáticas. A análise baseada em 10 experimentos e 25 genótipos mostrou correlação positiva e linear entre a severidade de mancha parda nas folhas e a mancha de grãos em arroz de terras altas, indicando o papel predominante das lesões nas folhas, causadas por $B$. oryzae, na incidência de mancha de grãos, além de outros fungos (16). A severidade da doença é alta quando a emissão das panículas coincide com chuvas contínuas dificultando a aplicação de fungicidas, sendo necessário a busca de outras práticas culturais mais viáveis, além do uso da resistência genética, dentro do manejo integrado da doença.

Os conhecimentos quanto à influência da adubação nitrogenada e a época de plantio na severidade de mancha de grãos em terras altas, em solos de cerrado, são limitados. A relação entre a mancha de grãos nas panículas e seus efeitos nos componentes de produção varia com o grau de suscetibilidade da cultivar. A presente investigação foi realizada visando identificar a incidência e a severidade de mancha de grãos no campo na cultivar de terras altas BRS Bonança; determinar os fatores que influenciam a mancha de grãos em arroz de terras altas; e avaliar a prevalência de fungos no ar após a emissão das panículas e a associação dos mesmos com a mancha de grãos.

\section{MATERIAL E MÉTODOS}

O experimento foi conduzido em Santo Antônio de Goiás,GO, na área experimental da fazenda Capivara (Latitude: $16^{\circ} 28^{\prime} 00^{\prime \prime}$ Longitude: 49¹7'00" Altitude: 823,00 metros), na Embrapa Arroz e Feijão, com irrigação suplementar por pivô central. O ensaio foi conduzido em uma área que teve como cultivo de verão o guandu [(Cajanus cajan (L.)Millsp.], sendo um Latossolo Vermelho Escuro Distrófico com as seguintes características químicas: $\mathrm{pH}\left(\mathrm{H}_{2} \mathrm{O}\right)=5,4 ; \mathrm{Ca}^{2+}=0,3$ $\mathrm{cmol}_{\mathrm{c}} \mathrm{dm}^{-3} ; \mathrm{Mg}^{2+}=0,1 \mathrm{cmol}_{\mathrm{c}} \mathrm{dm}^{-3} ; \mathrm{Al}^{3+}=0,4 \mathrm{cmol}_{\mathrm{c}} \mathrm{dm}^{-3} ; \mathrm{P}=26,6$ mg.dm ${ }^{-3} ; \mathrm{K}=62,6 \mathrm{mg} \cdot \mathrm{dm}^{-3} ; \mathrm{Cu}=1,9 \mathrm{mg} \cdot \mathrm{dm}^{-3} ; \mathrm{Fe}=40,0 \mathrm{mg} \cdot \mathrm{dm}^{-3} ; \mathrm{Mn}$ $=36,0 \mathrm{mg} \cdot \mathrm{dm}^{-3} ; \mathrm{MO}=22,0 \mathrm{~g} \cdot \mathrm{dm}^{-3}$. O delineamento experimental foi em blocos ao acaso em esquema de parcelas subdivididas, com três repetições. Os tratamentos foram 12 épocas de plantios semanais, da cultivar BRS Bonança, iniciando em 09/11/2006, e cinco doses de adubação nitrogenada. As parcelas consistiram de épocas de plantio e as subparcelas os níveis de nitrogênio.

A cultivar BRS Bonança foi semeada em parcelas de 10,5 $\mathrm{m}^{2}$ compostas de seis linhas de 5,0 $\mathrm{m}$ de comprimento. $\mathrm{O}$ espaçamento entre linhas foi de $0,35 \mathrm{~m}$ e a densidade de plantio foi de 90 sementes/ metro. A adubação de base utilizada foi de $264 \mathrm{~kg} \cdot \mathrm{ha}^{-1}$ de superfosfato simples, $96 \mathrm{~kg} \cdot \mathrm{ha}^{-1}$ de cloreto de potássio e cinco doses de nitrogênio $\left(0,30,60,120\right.$ e $240 \mathrm{~kg} \cdot \mathrm{ha}^{-1}$ de $\left.\mathrm{N}\right)$ na forma de sulfato de amônio. A adubação nitrogenada foi aplicada metade na ocasião do plantio e a outra metade aos 42 e 56 dias após o plantio. As sementes foram tratadas com o fungicida pyroquilon (400g.100 kg de sementes) para evitar altas severidades da brusone nas folhas.

Para estudar os fatores que afetam a mancha de grãos foram utilizados somente duas épocas de plantio (a primeira semeada em 30/ $11 / 2006$ e a segunda em 21/12/2006) e as cinco doses de N, em três repetições. As panículas emitidas na mesma época (50\% da panícula emitida) foram marcadas nas quatro linhas centrais, totalizando 40 panículas. A severidade da mancha de grãos foi avaliada em oito panículas/parcela em intervalos de cinco dias, aos 5, 10, 15, 20 e 25 dias após a emissão da panícula (DAEP), utilizando uma escala de cinco graus $(0=$ sem manchas; $1=1-25 \% ; 2=26-50 \% ; 3=26-50 \% ; 4=51$ $75 \%$ da superfície do grão manchada) e o índice de doença foi calculado pela fórmula ID $=\sum$ (valor de classe $\mathrm{x}$ freqüência de classe)/número total de grãos. Para estudar o efeito da época de plantio e da dose de nitrogênio sobre a severidade da mancha de grãos, esterilidade e o peso de 100 grãos, os dados coletados na penúltima época, no estágio de panícula madura foram submetidos à análise de variância e as médias foram comparadas pelo teste de Tukey $(\mathrm{P} \leq 0,05)$.

A população dos fungos no ar (aerosporos) foi quantificada 
utilizando armadilha volumétrica 'Rotorod Sampler'. Os bastões recobertos com silicone (General Electric G-697 lubrificante de silicone) foram expostos diariamente, desde a emissão até a maturação das panículas, por um período de duas horas/dia no período da manhã (09:00 às 11:00 h), em que se obtém os maiores picos de liberação de esporos. A concentração total de esporos foi estimada por meio de contagem ao acaso de 20 campos (40X) por bastão, em dois bastões com auxílio de microscópio. O número total de esporos por um total de 300 campos por dois bastões foi calculado. Após a determinação do número total de esporos capturados nos dois bastões, a concentração de esporos por volume de ar foi obtida pela fórmula: Concentração de esporos/volume de ar = Número total de esporos/RPM x K x T, onde: RPM é a rotação por minuto, $K$ uma constante $(0,05)$ e $T$ o período de funcionamento no campo (120 min).

Os dados coletados na estação meteorológica da Embrapa Arroz e Feijão, em Santo Antônio de Goiás, foram utilizados para estudar a correlação entre a temperatura máxima, mínima, precipitação e umidade, com a concentração de esporos de fungos, de 27/02 a 27/ 03/2007.

A análise de sanidade dos grãos foi feita pelo método blotter teste, conforme Regras para Análise de Sementes (2), utilizando-se 100 sementes por parcela num total de 15 parcelas (cinco doses de $\mathrm{N} x$ três repetições). As sementes foram distribuídas uniformemente em caixas tipo gerbox, contendo duas folhas de papel mata-borrão umedecidas com água destilada estéril. Os gerboxes contendo as sementes foram incubados por sete dias a $24^{\circ} \mathrm{C}$, umidade de $65 \%$ e fotoperíodo de 12 horas de luz ultravioleta e 12 horas de escuro. Após o período de incubação, foi feita a contagem e a identificação dos fungos presentes nas sementes, com auxílio de um microscópio estereoscópio, e quando necessário utilizou-se o microscópio de luz (2).

\section{RESULTADOS E DISCUSSÃO}

A análise de variância dos dados de severidade da mancha de grãos, em duas épocas de plantio e cinco doses de adubação nitrogenada, não mostrou diferença significativa, mas a interação entre essas duas variáveis foi significativa, como pode ser observado na Tabela 1.

A mancha de grãos apresentou diferença significativa entre épocas de plantio somente na dose de $240 \mathrm{~kg} \cdot \mathrm{ha}^{-1}$, apresentando severidade da doença significativamente maior na segunda época de plantio, como verificado na Tabela 1. A severidade da mancha de grãos foi baixa e atingiu o índice de 1,97 na primeira época de plantio em comparação a

Tabela 1. Efeito da época de plantio e doses de nitrogênio sobre a severidade da mancha de grãos, sob condições naturais de infecção no campo, na cultivar de arroz BRS Bonança.

\begin{tabular}{lcc}
\hline $\mathbf{N}\left(\mathbf{k g . h a}^{-1}\right)$ & Época $\mathbf{1}$ de plantio & Época 2 de plantio \\
\hline 0 & $1,74 \mathrm{aA} *$ & $2,33 \mathrm{aA}$ \\
30 & $2,18 \mathrm{aA}$ & $2,22 \mathrm{aA}$ \\
60 & $2,31 \mathrm{aA}$ & $2,40 \mathrm{aA}$ \\
120 & $1,96 \mathrm{aA}$ & $2,18 \mathrm{aA}$ \\
240 & $1,68 \mathrm{aA}$ & $2,62 \mathrm{aB}$ \\
$\mathrm{CV}(\%)$ & 12,6 & \\
\hline
\end{tabular}

*Médias seguidas pela mesma letra minúscula na coluna e maiúscula nas linhas não diferem entre si, pelo teste de Tukey, ao nível de $5 \%$ de probabilidade.
2,35 na segunda época, o que corresponde a $49,25 \%$ e $58,75 \%$ da superfície do grão afetada, respectivamente. A baixa incidência de mancha de grãos na cultivar BRS Bonança pode ser atribuída ao maior grau de resistência desta cultivar em relação a outras cultivares, como demonstrado nos testes realizados em arroz de terras altas, sob irrigação suplementar no Estado de São Paulo (11). Altas severidades da doença foram relatadas em solos pobres, arenosos e deficientes em nutrientes (25). No presente experimento, a cultura de inverno anterior (guandu) provavelmente supriu nutrientes adequadamente para a planta, inclusive para as parcelas onde se utilizou $\mathrm{N}$ na dose zero.

Os primeiros sintomas da mancha de grãos apareceram cinco dias após a emissão da panícula. A severidade da doença aumentou de maneira linear (Figura 1) em relação ao tempo $(\mathrm{r}=0,98 ; \mathrm{P} \leq 0,01)$, podendo ser atribuído à natureza policíclica da doença, causada por diversos fungos, e pelo aumento do grau de suscetibilidade das espiguetas. Testes realizados anteriormente com fungos patogênicos, como B. oryzae e Phoma sorghina (22) demonstraram alta suscetibilidade das espiguetas desde a emissão das panículas até o florescimento (1). As manchas causadas por fungos saprófitas ou fracamente patogênicos como Nigrospora sp. e Curvularia spp. podem aumentar na fase de amadurecimento e necessitam estudos de patogenicidade em relação a diferentes estádios de desenvolvimento dos grãos.

A correlação entre a severidade de mancha de grãos e espiguetas vazias foi positiva (Figura 2). Este resultado está de acordo com os obtidos anteriormente com outras cultivares de arroz de terras altas $(11,15,19)$.

Os fungos no ar coletados pela armadilha volumétrica não aumentaram da mesma maneira que a mancha de grãos aumentou no campo. O aumento total de fungos diários capturados pela armadilha volumétrica variou de 0,22 a 2,96 esporos/litro de ar/minuto entre os dias 27/02 e 27/03 de 2007, durante a formação de grãos, dependendo das condições climáticas. Os fungos presentes no ar, capturados pela armadilha volumétrica (Figura 3) em ordem decrescente de incidência foram: Nigrospora sp., Pyricularia oryzae, Pithomyces sp., Alternaria sp., Cercospora sp., Fusarium sp., Curvularia sp. e Bipolaris sp.

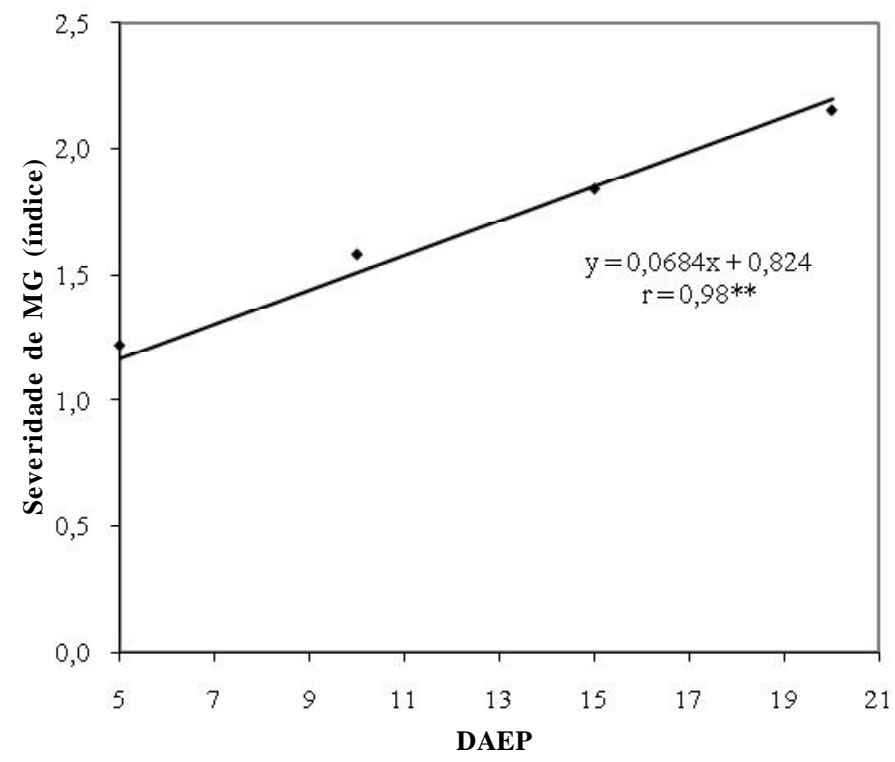

Figura 1. Severidade da mancha de grãos (MG) em relação ao tempo, dias após a emissão de panículas (DAEP). ** Significativo ao nível de $1 \%$ de probabilidade. 


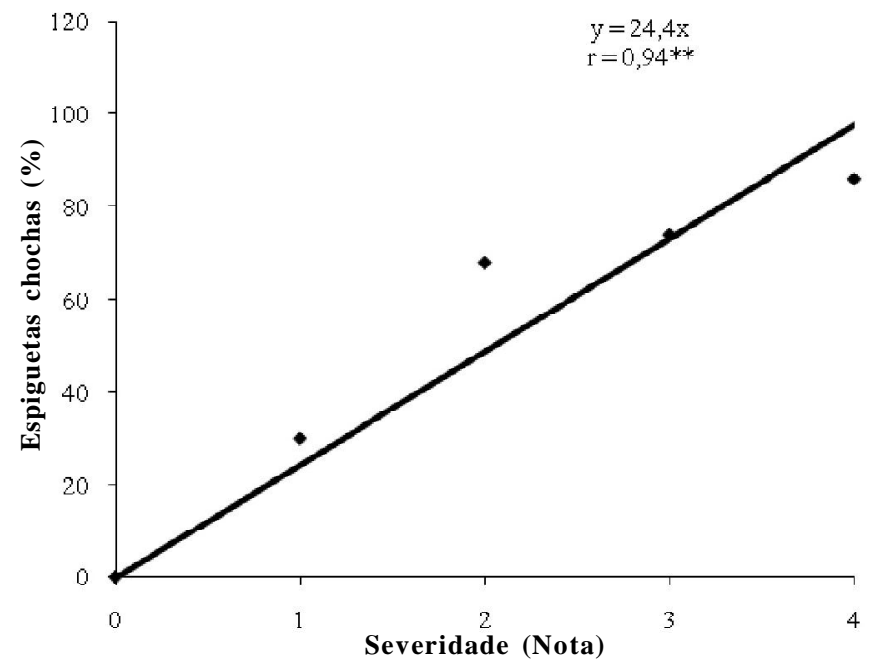

Figura 2. Efeito da severidade da mancha de grãos sobre a esterilidade de grãos. **Significativo ao nível de $1 \%$ de probabilidade.

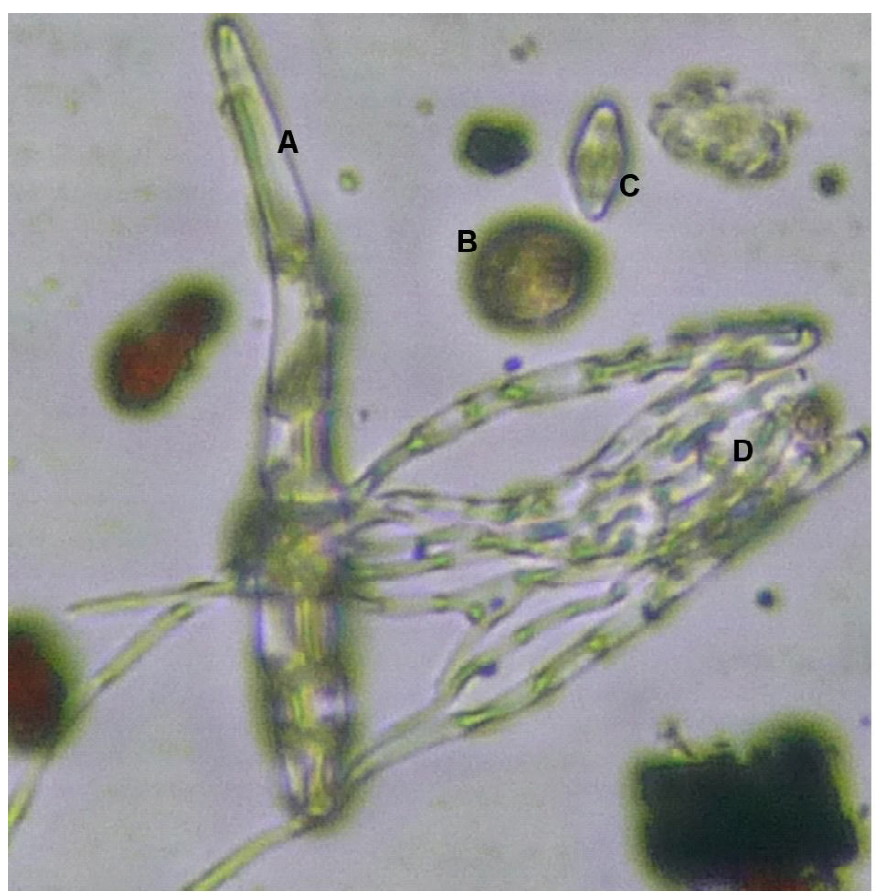

Figura 3. Fungos coletados pela armadilha Rotorod-sampler e observado em microscópio ótico (40X) onde: A:Altenaria padwickii, B: Nigrospora sp, C: Pyricularia oryzae e D: Cercospora oryzae.

(Figura 4). As altas concentrações de esporos de Pyricularia oryzae podem ser atribuídas a alta suscetibilidade da cultivar BRS Bonança à brusone.

O aumento diário de fungos foi influenciado por fatores climáticos. O número de esporos aumentou com aumento da umidade relativa e diminuiu com aumento da temperatura máxima de maneira exponencial (Figura 5). Infecções de grãos no campo geralmente são afetadas pelas condições climáticas, especialmente umidade (13).

A concentração de esporos de Pyricularia oryzae foi altamente correlacionada com o número total dos outros fungos (Figura 6). As altas concentrações de esporos de Nigrospsora sp., durante toda a

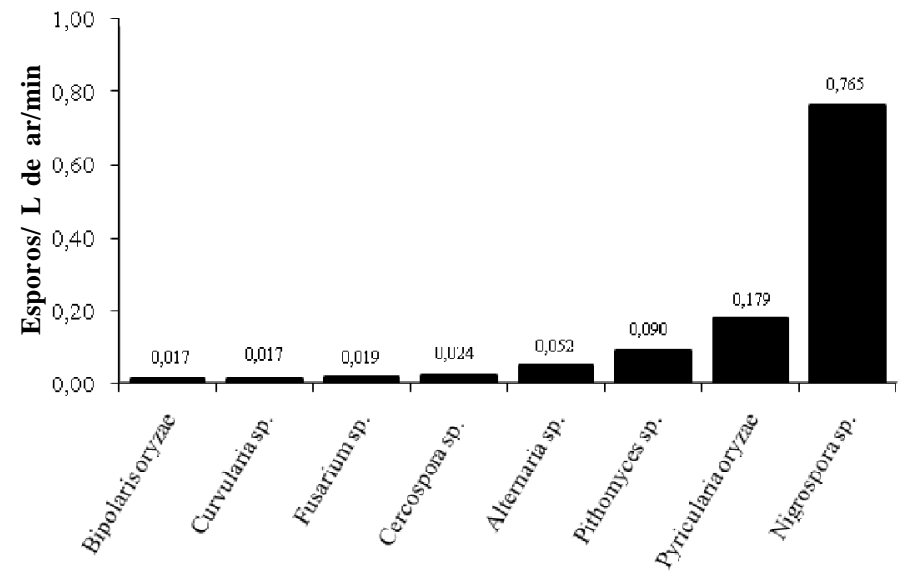

Figura 4. Principais fungos manchadores de grãos, coletados com armadilha volumétrica Rotorod Sampler após a emissão das panículas da cultivar de arroz BRS Bonança, no campo.

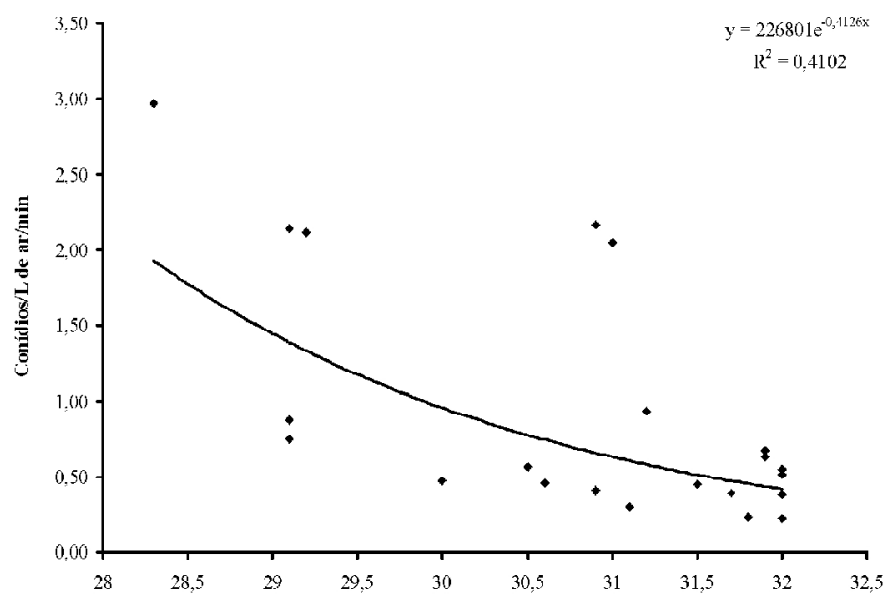

A

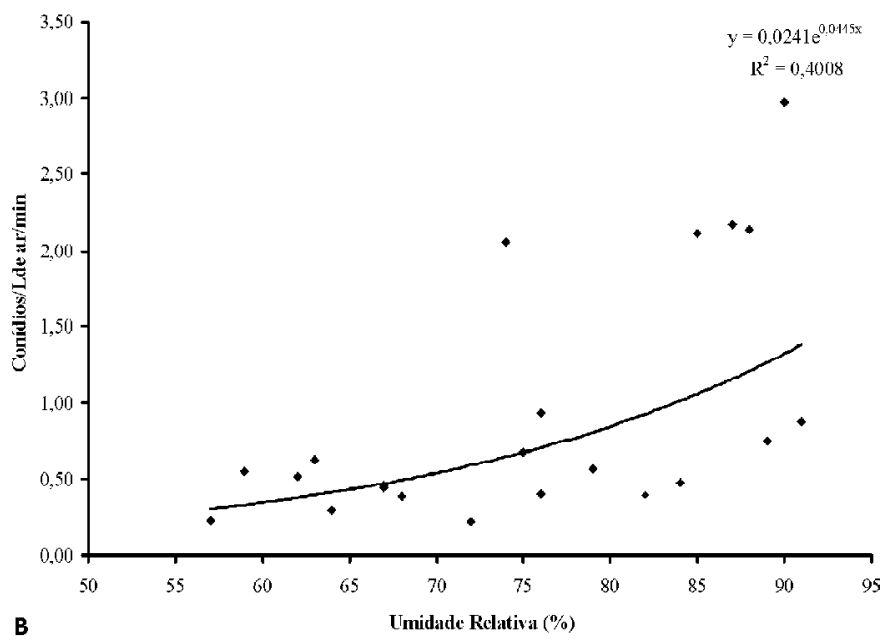

Figura 5. Efeito da temperatura máxima (A) e da umidade relativa do ar (B) na produção de conídios de fungos no ar, após a emissão de panículas da cultivar BRS Bonança. 


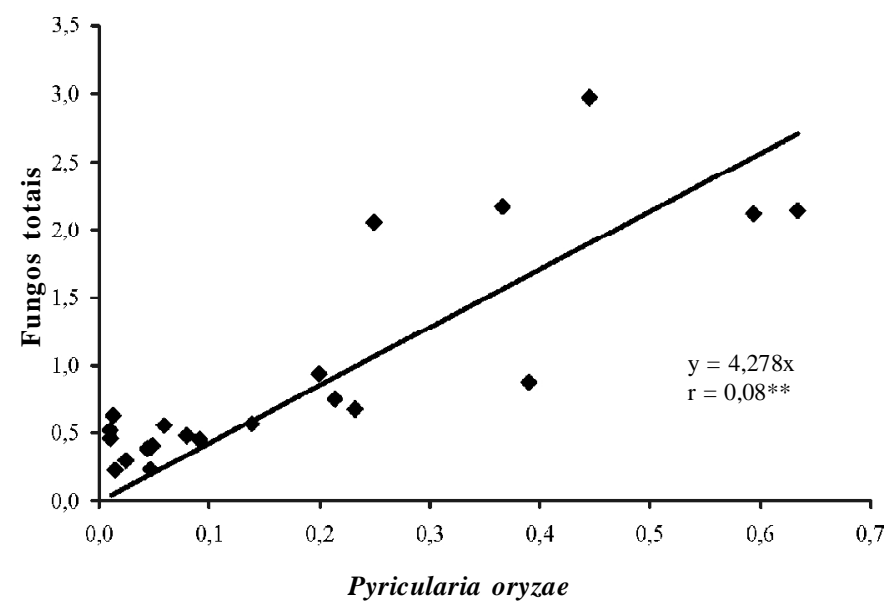

Figura 6. Relação entre a concentração de conídios (litro de ar/min) de Pyricularia oryzae no ar e conídios de fungos totais coletados pela armadilha Rotorod Sampler exposto no campo de arroz BRS Bonança. ** Significativo ao nível de $1 \%$. de probabilidade.

coleta de esporos pode ser atribuída a sua capacidade de esporulação e multiplicação nas folhas baixeiras e senescentes do arroz. Nos estudos realizados na Índia sobre aerosporos em arroz foram encontrados, em maior frequência, os gêneros Nigrospora, Fusarium, Helminthosporium e Curvularia (23).

Estes fungos e Phoma sp. também foram detectados nos grãos pelo método de blotter test em laboratório (Figura 7). Os fungos associados à mancha de grãos em ordem de maior frequiência foram Phoma sorghina, Fusarium sp., Cladosporium sp., Nigrospora sp., Curvularia sp., Epiccocum sp., Bipolaris oryzae, Pyricularia oryzae e outros.

A alta concentração de esporos de Nigrospora sp. no ar indica seu papel como um dos principais fungos associados com a mancha de grãos no final do ciclo da cultura do arroz. As espécies de Nigrospora são saprófitas comuns que ocorrem em partes senecentes das plantas e uma das causadoras de manchas minutas de folhas e grãos de arroz. Pústulas pequenas de cor preta, de tamanho até 5,0 $\mathrm{mm}$ de diâmetro ocorrem nas partes infectadas das plantas, inclusive folhas e grãos (24). Quatro espécies de Nigrospora (N. oryzae (Berk. \& Broome) Petch, $N$. spherica (Scc.) E. Mason, $N$. panici Zimmerm, N. padwickii Prasd, A Gnihotri \& Agrawal) foram registradas em diferentes partes de mundo (13).

No presente trabalho a incidência do fungo $B$. oryzae na cultivar BRS Bonança foi baixa. Entre os patógenos de arroz, o fungo $D$. oryzae seguido por Phoma sp., G. oryzae e P. oryzae foram os que ocorreram com maior freqüência em cinco localidades da região CentroOeste analisadas. Outros fungos como Phoma spp. Curvularia spp. Fusarium spp., Nigrospora sp. e A. padwickii contribuiram significativamente para a ocorrência da mancha de grãos em arroz de terras altas também no Centro-Oeste (19). Todos estes fungos são comuns e foram relatadas nos levantamentos de sanidade de sementes realizadas em outros países (12).

A associação de $P$. oryzae com grãos nos testes de sanidade de sementes e a alta concentração de esporos no ar foi devido a maior sucetibilidade da cultivar BRS Bonança a este patógeno. A alta incidência de $P$. sorghina e a sua ausência nos bastões pode ser explicada pela dificuldade de capturar e de identificar esporos de tamanho muito pequeno. No entanto, o fungo Phoma sp. foi observado em maior freqüência no levantamento de fungos associados com manchas de grãos no Centro-Oeste (19).

A incidência de fungos como A. padwickii, considerado um dos patógenos de arroz altamente transmissível pelas sementes e economicamente importante foi baixa. A baixa incidência também foi observada em cultivares de arroz de terras altas no Estado de São

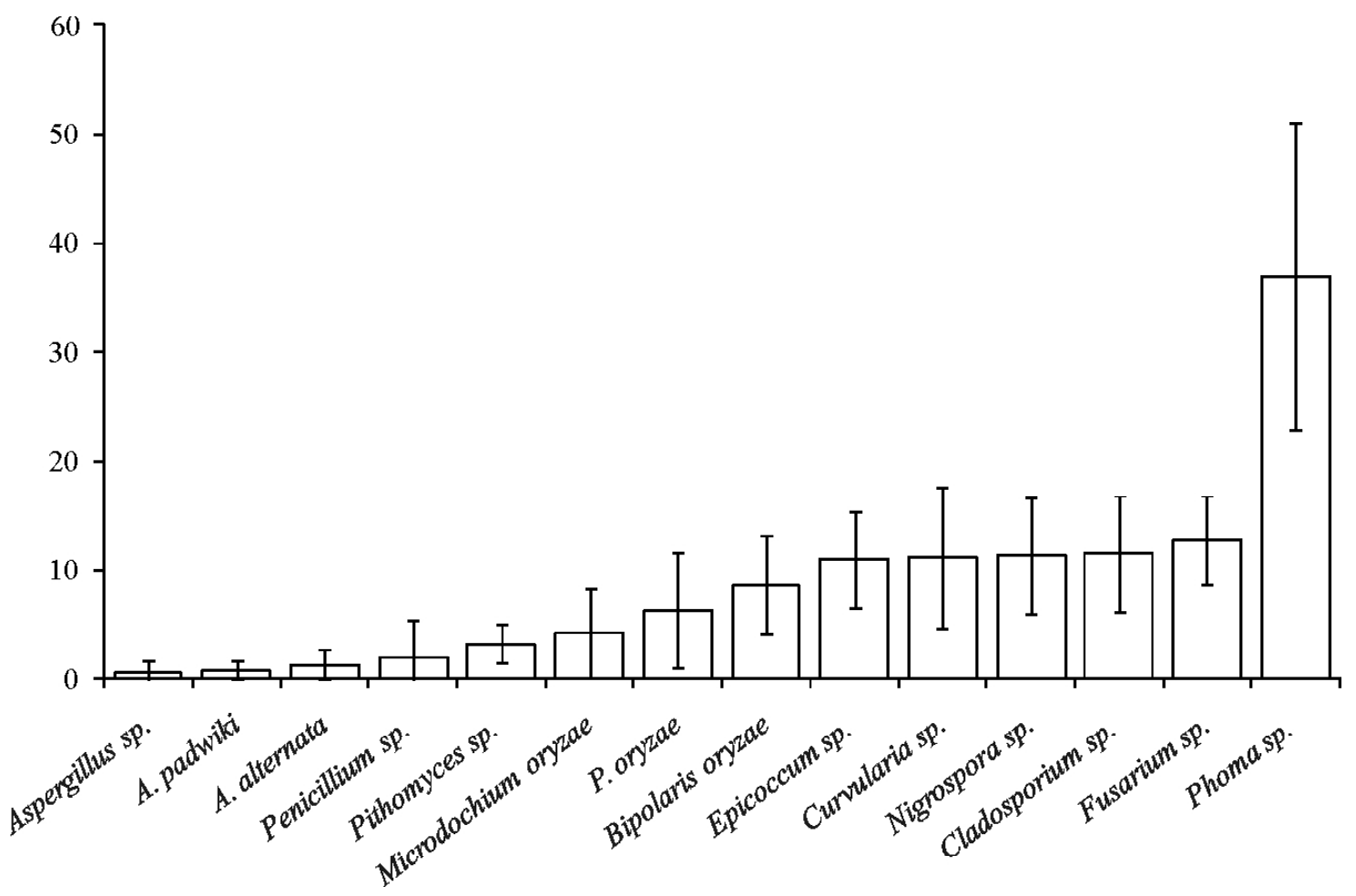

Figura 7. Fungos detectados pela análise de sanidade de sementes pelo método blotter test. 
Paulo (11). Incidências deste patógeno, variando de 1,78 a 10,61\% em média, foram observadas em sementes de arroz irrigado, dependendo da cultivar e do local $(5,8)$. Este fungo ocupou o primeiro lugar entre os patógenos associados com sementes nos testes realizados no IRRI, em 4744 lotes de sementes avaliados, o fungo foi observado em $96.9 \%$ dos lotes (12). A incidência de A. padwickii variou de 1,33 a 40\%, conforme as cultivares avaliadas em Taipei (9).

Os resultados do presente trabalho permitem concluir que a mancha de grãos na cultivar BRS Bonança causou esterilidade de grãos. A adubação nitrogenada não influenciou na incidência da mancha de grãos, enquanto que a época de plantio aumentou a severidade da

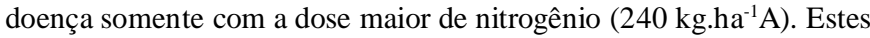
resultados são aplicáveis somente nas condições em que foi conduzido o experimento. A temperatura máxima e a umidade relativa do ar foram os principais fatores que influenciaram na concentração de esporos no ar durante a formação de grãos.

\section{REFERÊNCIAS BIBLIOGRÁFICAS}

1. Bedendo, I.P.; Prabhu, A.S. Um método de avaliação de germoplasma de arroz para resistência a mancha parda nos grãos. Fitopatologia Brasileira, Brasília, DF, v.7, n.5, p.572-572, 1982.

2. Brasil. Ministério da Agricultura e Reforma Agrária. Regras para análise de sementes. Brasília; DF:SNDA,DNDV,CLAV, 1992. $365 \mathrm{p}$.

3. Chattopadhyay, S.B.; Dickson, J.G. 1960. Relation of nitrogen to disease development in rice seedlings infected with Helminthosporium oryzae. Phytopathology, Saint Paul, v.50, n.6, p.434438, 1960.

4. Cornelio, V.M.O.; Carvalho, V.L.; Prabhu, A.S. Doenças de arroz. Informe Agropecuário, Belo Horizonte, v.25, n.222, p.84-92, 2004.

5. Costa, J.L.S. Alternaria padwickii e Curvularia lunata: Patogencidade e transmissão por semente de arroz irrigado. Fitopatologia Brasileira, Brasília, DF, v.16, n.1, p.15-18, 1991.

6. Desprez-Loustau, M.L., Robin, C.; Reynaud, G. et al. Simulating the effects of a climate-change scenario on the geographic range and activity of forest-pathogenic fungi. Canadian Journal of Plant Pathology, Burnaby, BC, v.29, n.2, p.101-120, 2007.

7. Faria, J.C.; Prabhu, A.S. Relação entre fertilização nitrogenada e mancha parda do arroz em solos de cerrado. Pesquisa Agropecuária Brasileira, Brasília, DF, v.18, n.12, p.1377-1379, 1983.

8. Farias, C.R.J. de; Afonso, A.P.S.; Brancão, M.F; Pierobom, C.R. Ocorrência de Alternaria padwickii (Ganguly) em sementes de arroz (Oryza sativa L.) (Poaceae) produzidas em quatro regiões orizícolas do Rio Grande de Sul e seu efeito sobre plântulas. Arquivos do Instituto Biológico, São Paulo, v.74, n.3, p.245249, 2007.

9. Islam, M.S.; Jahan, Q.S.; Bunnarith, K.; Viangkum, S.; Merca, S.D. Evaluation of seed health of some rice varieties under different conditions. Botanical Bulletin of Academia Sinica, Taipei, v.41, n.4, p.293-297, 2000.
10. Malavolta, V.M.A.; Bedendo, I.P. Resistência de cultivares de arroz a manchas de grãos causadas pelos fungos Bipolaris oryzae, Microdochium oryzae e Phoma sorghina. Summa Phytopatologica, Jaboticabal, v.25, n.4, p.313-318, 1999.

11. Malavolta, V.M.A.; Soligo, E.A.; Dias, D.D.; Azzini, L.E.; Bastos, C.R. Incidência dos fungos e quantificação de danos em sementes de genótipos de arroz. Summa Phytopatologica, Botucatu, v.33, n.3, p.280-286, 2007.

12. Mew, T.W.; Bridge, J.; Hibino, H.; Bonman, J.M.; Merca, S.D Rice pathogens of quarantine importance. In: Rice Seed Health: International Tice Research Institute, Los Banos, Philippines. p.101-115, 1988.

13. Ou, S.H. Rice diseases. 3 ed. Kew: Commonwealth Mycological Institute, $1987.368 \mathrm{p}$.

14. Prabhu, A.S.; Bedendo, I.P. Glume blight of rice in Brazil: etilogy, varietal reaction and loss estimates. Tropical Pest Manage, London, v.34, n.1, p.85-88, 1988.

15. Prabhu, A.S; Soave, J.; Zimmerman, F.J.P.; Filippi, M.C.; Souza, N.R.G.; Curvo, R.C.V.; Sobral, C.A.M.; Lopes, A.M; Ferreira, M.P.; Kobayashii, T.; Galvão, E.U.P. Genetic variability for disease resistance in Brazilian upland rice germplasm. Pesquisa Agropecuária Brasileira, Brasília, DF, v.31, n.3, p.413-424, 1996.

16. Ribeiro, A.S. Fungos encontrados em sementes de arroz no Rio Grande do Sul. Fitopatologia Brasileira, Brasília, DF, v.5, n.1 p.59-65, 1980 .

17. Saifulla, M; Krishnappa,K.; Prakash,H.S.; Shetty, H.S. Agronomic practices on the incidence of rice grain discoloration. Agricultural Science Digest, Nova Delhi, v.15, n.3, p.125-128, 1995

18. Soave, J.; Pizzinatto, M.A.; Usberti Junior, J.A.; Camargo, O.B.A.; Villela, O.V. Selection of rice pathogen using seed health testing. Pesquisa Agropecuária Brasileira, Brasília, DF, v.19, n.4, p.449-453, 1984.

19. Soave, J.; Prabhu, A.S.; Ricci, M.T.; Barros, L.G.; Souza, N.R.G.; Curvo, R.C.V. Ferreira, R.P.; Sobral, C.A.M. Etiologia de manchas de sementes de cultivares de arroz de sequeiro no CentroOeste brasileiro. Summa Phytopathologica, Jaboticabal, v.23, n.2, p.122-127, 1997.

20. Souza, N.R.G.; Curvo, R.V.C.; Prabhu, A.S.; Barros, L.G. de. Ocorrência e severidade de doenças do arroz de sequeiro no Estado do Mato Grosso. In: Reunião Nacional de Pesquisa de Arroz, 3., Goiânia, 1987. Anais. Goiânia: EMBRAPA;CNPAF, 1991. p. 483-509. (EMBRAPA-CNPAF. Documentos, 25).

21. Souza, N.S. de; Barros, L.G. de; Prabhu, A.S. Incidência da mancha de grãos em relação à época de plantio e aplicação de fungicidas. Boletim de Pesquisa EMPAER, Várzea Grande, n.4, 1994. 20p.

22. Souza, N.S.; Zambolim, I. Resistance vertical de arroz (Oryza sativa) à queima das glumelas (Phoma sorghina). Fitopatologia Brasileira, DF, Brasília, v.12, n.1, p.50-52, 1987.

23. Uddin, N. Airospora studies over a rice (High yielding variety) field in Rabi season in the State of West Bengal, India. Aerobiologia, Berlin, v.20, n.2, p.127-134, 2004.

24. Webster, R.K.; Gunnell, P.S. Compendium of rice diseases The American Phytopathological Society, St. Paul, 1992. 86p.

25. Winslow, M.D. Silicon disease resistance and yield of rice genotypes under upland cultural conditions. Crop Science, Madison, v.32, n.5, p.1208-1213, 1992. 